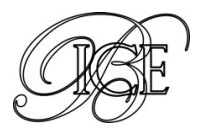

Subdirección General de Análisis Estratégico y Sistema Financiero Internacional*

\title{
LAS ASAMBLEAS ANUALES DEL FONDO MONETARIO INTERNACIONAL EN LIMA Octubre de 2015
}

Las Asambleas del FMI celebradas en Lima se han visto marcadas por los fuertes cambios en la economía mundial a lo largo de este año. Los países emergentes, tras años de un fuerte crecimiento, experimentan una importante desaceleración, relacionada con las caídas en los precios de las materias primas y en los flujos de capitales. Brasil y Rusia están sufriendo graves recesiones. La región iberoamericana se ha visto considerablemente afectada, pero los países con políticas económicas más prudentes destacan por su mayor resistencia a la crisis. Por su parte, los países desarrollados continúan recuperándose de la crisis de forma gradual. La zona euro ha conseguido salir de su estancamiento, y dentro de ella España destaca por su notable nivel de crecimiento.

El FMI se ha mantenido a la espera de la ratificación por parte de los Estados Unidos de la reforma de cuotas y gobierno de 2010, que permitirá reflejar mejor en su estructura institucional las realidades de la economía mundial. Las expectativas de entrada del yuan chino en la cesta de los derechos especiales de giro y el refuerzo del papel del Fondo en la reforma estructural han sido las principales cuestiones institucionales que se han debatido en estas Asambleas.

Palabras clave: instituciones financieras internacionales, economía mundial, países emergentes. Clasificación JEL: F01, F33.

\section{Introducción}

Las Asambleas Anuales del Fondo Monetario Internacional (FMI) y del Banco Mundial reúnen cada otoño a los ministros de Economía o Hacienda y a los gobernadores de bancos centrales de sus países miembros, que ahora mismo ascienden a 188. Dentro de los calendarios de las Asambleas se celebran también las reuniones de los principales grupos de economías desarrolladas y emergentes, como el G-20, el G-7, los BRICS o el G-24. Estas

* Este artículo ha sido elaborado por Miguel Ángel Martínez Rolland. Versión de diciembre de 2015. reuniones presentan una oportunidad para orientar el trabajo de las instituciones financieras internacionales, que constituyen los principales pilares de la arquitectura financiera internacional, así como para tomar el pulso a la economía mundial y efectuar valiosos contactos bilaterales entre autoridades económicas de alto nivel. También, aprovechando la concentración de autoridades, sirven para reunir a los principales representantes del sector financiero, empresarios, académicos y representantes de sindicatos, fundaciones y otros grupos de la sociedad civil. En los márgenes de las Asambleas, se producen numerosos contactos de alto nivel y acuerdos entre $D$ 


\begin{tabular}{|c|c|c|c|}
\hline \multicolumn{4}{|c|}{$\begin{array}{c}\text { TABLA } 1 \\
\text { CRECIMIENTO DEL PIB MUNDIAL }\end{array}$} \\
\hline Crecimiento del PIB & 2014 & $2015(P)$ & $2016(P)$ \\
\hline Mundo & 3,4 & 3,1 & 3,6 \\
\hline Economías avanzadas ................................... & 1,8 & 2,0 & 2,2 \\
\hline 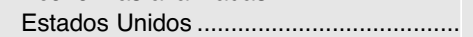 & 2,4 & 2,6 & 2,8 \\
\hline Área euro & 0,9 & 1,5 & 1,6 \\
\hline Alemania. & 1,6 & 1,5 & 1,6 \\
\hline 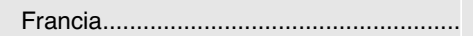 & 0,2 & 1,2 & 1,5 \\
\hline 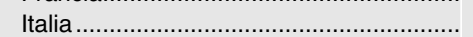 & $-0,4$ & 0,8 & 1,3 \\
\hline España & 1,4 & 3,1 & 2,5 \\
\hline 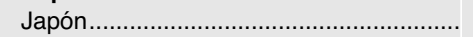 & $-0,1$ & 0,6 & 1,0 \\
\hline 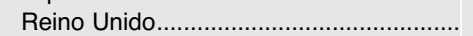 & 3,0 & 2,5 & 2,2 \\
\hline Países emergentes y en desarrollo......... & 4,6 & 4,0 & 4,5 \\
\hline China & 7,3 & 6,8 & 6,3 \\
\hline 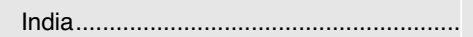 & 7,3 & 7,3 & 7,5 \\
\hline 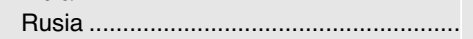 & 0,6 & $-3,8$ & $-0,6$ \\
\hline América Latina y el Caribe $\ldots \ldots \ldots \ldots \ldots \ldots . . . . . . . . . . .$. & 1,3 & $-0,3$ & 0,8 \\
\hline 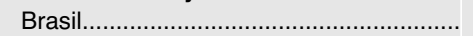 & 0,1 & $-3,0$ & $-1,0$ \\
\hline 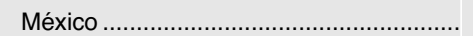 & 2,1 & 2,3 & 2,8 \\
\hline Oriente Medio y África del Norte ............... & 2,7 & 2,5 & 3,9 \\
\hline África subsahariana & 5,0 & 3,8 & 4,3 \\
\hline
\end{tabular}

empresas, y se celebran presentaciones (road shows) e importantes seminarios sobre las cuestiones económicas de máxima actualidad.

Cada tres años, las Asambleas Anuales de otoño se celebran fuera de Washington DC, que es la sede de las instituciones financieras internacionales, para atraer la atención sobre una región o un país que se ofrezca a organizarlas. Para 2015 la ciudad elegida ha sido Lima, en Perú, que se ha convertido durante una semana en la «capital económica del mundo». Es la primera ciudad hispanohablante desde Madrid en 1994 en acoger estas reuniones, y la primera en lberoamérica desde 1967, cuando se celebraron las Asambleas en Río de Janeiro'. El esfuerzo logístico y organizativo de las autoridades peruanas ha sido muy considerable, con aproximadamente 30.000 personas acreditadas e importantes necesidades de infraestructuras y alojamiento. Pero estas reuniones también atraen un importante volumen de negocio para el país, así como una importante proyección en términos de imagen para Perú y de atención para la región iberoamericana.

1 La otra ciudad hispanoamericana en la que se han celebrado las Asambleas en la Ciudad de México, en 1952.
En este artículo analizaremos las principales tendencias de la economía mundial que se han tratado en las Asambleas del FMI, para continuar con los debates institucionales que se han producido en él.

\section{Principales tendencias de la economía mundial}

El principal foco de atención sobre la economía mundial se ha situado sobre la desaceleración de los países emergentes. Tras una década y media de fuerte crecimiento en los países emergentes y en desarrollo (con una media del 6 por 100 hasta 2014), se aprecia una notable desaceleración para 2015 (un crecimiento previsto de casi el 4 por 100), pero con una fuerte heterogeneidad por regiones y países. Así Asia emergente sigue creciendo a tasas elevadas (sobre todo India y China), países muy significativos como Brasil y Rusia están experimentando graves recesiones, superiores al -3 por 100. Los flujos de capitales a los países emergentes han caído aceleradamente, e incluso han tenido signo negativo en los últimos trimestres. El comercio mundial se sigue desacelerando, exhibiendo un crecimiento interanual del 3,2 por 100 en volumen. 
La situación de la economía de China ha ocupado una parte importante de la atención de las Asambleas. Tras haber experimentado un verdadero crack bursátil desde principios de año, las turbulencias financieras se extendieron desde China al resto del mundo en agosto, cuando el Gobierno chino anunció tres devaluaciones, aunque pequeñas, del yuan. Los análisis apuntaban a un estancamiento de la economía china, que ha contribuido a la tendencia marcadamente bajista de las materias primas, dado que China es hoy día su principal importador. Los datos de estancamiento de la producción industrial y de contracción de las importaciones chinas llevaron a algunos analistas privados a cuestionar las previsiones de crecimiento de China, considerando que podría estar experimentando un crecimiento inferior a lo estimado. Pese a este conjunto de noticias y al sentir del mercado, el personal del FMI ha mantenido su misma previsión de crecimiento de principios del verano, cercanas al 7 por 100. Estas previsiones están en línea con las de las autoridades chinas, que transmitieron confianza en que su economía mantendrá un alto nivel de crecimiento pese a un importante «reequilibrio", con cambios en su composición. Estiman que el consumo está creciendo a tasas elevadas, y junto a los servicios compensarán el menor crecimiento industrial. Esta firme postura de las autoridades chinas, y el respaldo del FMI, han reducido considerablemente los temores a nuevas devaluaciones del yuan, que eran temidas por los mercados financieros como una manera de apoyar el crecimiento chino, pero perjudicando las exportaciones y la producción industrial del resto del mundo.

Otro gran tema de la coyuntura económica, en estas Asambleas Anuales, ha sido la fuerte contracción de los precios de las materias primas en este año. Como principales causas de este fenómeno se ha apuntado a la moderación y recomposición del crecimiento chino, así como a la fortaleza del dólar, asociada a las expectativas de subidas de tipos y normalización de la política monetaria en Estados Unidos. Las principales regiones productoras de materias primas afectadas han sido Rusia y su ámbito económico de la Comunidad de Estados Independientes, así como Oriente Medio y norte de África, seguidas de América Latina y África subsahariana. Las monedas de los países más afectados están sufriendo fuertes presiones depreciatorias, lo que está generando preocupación para los países con mayores emisiones de deuda corporativa en moneda extranjera. Por otra parte, el descenso en los precios de las materias primas está siendo un factor muy positivo para las economías avanzadas ${ }^{2}$, que les ha permitido mejorar sus niveles de crecimiento, y ha contribuido a sus bajos niveles de inflación.

La situación económica de América Latina ha cobrado un importante protagonismo, en particular por celebrarse las Asambleas en Perú. Muchos países de la región son importantes productores de materias primas, que constituyen una parte importante de sus exportaciones, de su producción nacional y de su recaudación fiscal. Pero el impacto de los bajos precios ha diferido en función de la dependencia de las materias primas, de la calidad de las políticas económicas y de algunos factores específicos de cada país. Brasil, que es la economía más grande de la región, está atravesando una muy grave crisis económica, con una contracción estimada del PIB del 3 por 100 para este año. Se ha combinado el efecto de los precios de las materias primas con un agotamiento de su ciclo de crédito, tras años de crecimientos muy elevados, junto con presiones inflacionistas y sobre el déficit público. El FMI también ha mencionado el «deterioro político» como un factor importante que está pesando sobre la coyuntura del país.

Otros países iberoamericanos también están sufriendo crisis. Venezuela está experimentando una histórica implosión de su economía, con una contracción estimada del PIB del -10 por 100 este año y del -6 por 100 el próximo, combinada con una inflación muy elevada (160 por 100 anual) y la pérdida de sus reservas de divisas. Ecuador también $\triangle$

2 Salvo para Canadá, Australia y Noruega, que son las principales economías avanzadas con importante dependencia de las materias primas. 
está viviendo una ligera recesión (-0,6 por 100), y el FMl estima que Argentina está en práctico estancamiento este año, y en recesión el próximo³.

En cambio, otros países como México, Chile, Perú, Colombia y Uruguay mantienen crecimientos en torno al 2,5 por 100 anual, pese a ser también importantes productores de materias primas. Son países que cuentan con mayores colchones de política económica y han acumulado menores desequilibrios a lo largo de la década pasada. Estos países han adoptado además regímenes de política monetaria con importante credibilidad, y han mantenido una flexibilidad cambiaria moderada, que ha permitido amortiguar el impacto sobre el crecimiento. Esto contrasta con lo sucedido en la década de 1980, que también fue una época de bajos precios de las materias primas, reversión en los flujos de capitales internacionales y fortaleza del dólar. Entonces se produjeron graves crisis de balanza de pagos y fiscales en toda la región, con brotes hiperinflacionistas. Hoy la mayor parte de estas economías parecen mucho más sólidas ante la crisis, principalmente por la mejor gestión de política económica y la mejora institucional. Cuentan con apreciables reservas en divisas (en particular Brasil) y en el caso de México y Colombia, con líneas de crédito precautorias con el FMl ${ }^{4}$ que certifican la alta calidad de sus políticas económicas. Bolivia y Centroamérica, por su parte, están manteniendo crecimientos en torno al 4 por 100 este año.

Los países exportadores de hidrocarburos en Oriente Medio se cuentan entre los más afectados por la crisis de las materias primas, aunque principalmente en sus cifras de déficit público (el FMl estima un descomunal déficit público en Arabia Saudí e Irak, del 22 por 100 del PIB $^{5}$ y de casi el 15 por

\footnotetext{
3 Aunque cabe señalar que el FMI, en su informe sobre Perspectivas Económicas Mundiales (World Economic Outlook) hace explícitas sus reservas sobre las estadísticas argentinas, sobre las que hizo una declaración de censura en 2013. Incluso suministra datos de América Latina excluyendo a Argentina.

4 Las denominadas «Líneas de Crédito Flexible», que ascienden a 47.292 millones de derechos especiales de giro (MDEG) para México y 3.870 MDEG para Colombia. Las reservas de divisas de Brasil ascienden a la importante cifra de $\mathbf{3 6 0 . 0 0 0}$ millones de dólares en octubre de 2015.

5 Cabe mencionar el descalabro económico de Libia, para quien el FMI estima un déficit público del 79 por 100 del PIB y un déficit por cuenta corriente del 62 por 100 del PIB en 2015, propios de economías en guerra, tras una recesión del -24 por 100 en 2014 y del -6 por 100 en 2015.
}

100 en Argelia) y en su saldo exterior, que se ha deteriorado muy aceleradamente desde 2013. En cambio, para 2016 el Fondo prevé una notable recuperación en Irán por la suavización de las sanciones internacionales.

Para los países avanzados las perspectivas de crecimiento han mejorado, en concreto en la zona euro. Tras el estancamiento de 2014, la eurozona se recupera gradualmente este año, con un crecimiento a niveles del 1,5 por 100 . Dentro de la unión monetaria destaca particularmente el fuerte crecimiento de España, que el FMI estima en el 3,1 por 100 para este año. No obstante, el crecimiento en la zona euro todavía es apreciablemente inferior al esperado para los Estados Unidos (2,6 por 100). En este contexto, se mantiene el otro gran tema protagonista de la coyuntura actual en este año: las perspectivas de progresiva normalización de la política monetaria en Estados Unidos, con expectativas de subidas de tipos de interés en próximos trimestres. Estas perspectivas son las que sustentan la fortaleza del dólar y afectan a los precios de las materias primas y a los flujos de capital de los países emergentes que han tenido signo negativo. También están afectando a la volatilidad de los mercados financieros: hay incertidumbre sobre cómo reaccionarán los mercados a la primera subida de tipos en EEUU en casi diez años.

Junto a la volatilidad en los mercados financieros, entre los principales riesgos para la economía mundial que se han comentado en estas Asambleas, están los niveles de endeudamiento en moneda extranjera de las empresas de los países emergentes, así como el riesgo de crisis en países productores de materias primas. Pese a que estos países cuentan con importantes colchones de reservas en divisas acumuladas tras años de bonanza por los altos precios de sus exportaciones, las necesidades de ajuste pueden superar a las reservas disponibles si los precios siguen manteniéndose bajos. En los países desarrollados, se mantiene la preocupación por el bajo crecimiento de la productividad y los bajos niveles de inversión. En algunos casos, particularmente en la eurozona y $\triangleright$ 
Japón, los niveles de inflación son históricamente bajos, pero ha bajado la preocupación por el riesgo de presiones deflacionistas tras las nuevas medidas no convencionales de política monetaria que han adoptado.

\section{El papel del FMI y sus políticas}

Sobre las Asambleas Anuales de Lima ha pesado la falta de ratificación de la reforma del gobierno del FMI, que se demora desde hace casi cinco años. En diciembre de 2010, la Junta de Gobernadores del Fondo aprobó la reforma más importante de su sistema de cuotas y gobierno desde hace más de dos décadas. Con esa reforma se aprobó una duplicación de los recursos financieros propios del Fondo (sus "cuotas») y se trató de acercar la composición del accionariado a las realidades de la economía mundial. En particular, se trató de reflejar el peso ascendente de economías emergentes como China o México, así como reconocer el peso de economías que llevaban décadas infrarrepresentadas, como España. El peso de España en la institución pasará del 1,69 por 100 actual hasta un 2 por 100 con la reforma de cuotas y gobierno de 2010 -y el peso de China pasará del 4 por 100 al 6,39 por 100- pasando a ser el tercer mayor accionista (tras EEUU y Japón), cuando ahora mismo está por detrás de Alemania, Reino Unido y Francia.

La reforma implicaba una enmienda al Convenio Constitutivo del FMI, que tiene rango de tratado internacional, y por lo tanto ha tenido que ser sometida a la ratificación de los distintos parlamentos. La práctica totalidad de los miembros han conseguido su aprobación parlamentaria, salvo el mayor accionista, Estados Unidos. No es un hecho completamente nuevo, puesto que ha ocurrido en el pasado con reformas importantes de la organización económica internacional en momentos en que el poder ejecutivo de los EEUU y su poder legislativo han tenido distinto signo político. No obstante, este periodo de impasse está siendo particularmente largo en relación con episodios anteriores, y ha conducido a una cierta impaciencia en los países emergentes, particularmente en los momentos en que estaban creciendo a mayor velocidad.

Estados Unidos ha transmitido un mensaje claro de confianza en el que el bloqueo político está a punto de resolverse y la ratificación es inminente. Esto ha reducido la presión para adoptar algunas partes por separado de la reforma de 2010 de forma interina. $Y$ también resulta difícil contemplar nuevas reformas sustantivas dada la dificultad que ha habido en ratificar la de 2010. En todo caso, todo el trabajo sobre futuras reformas en el gobierno y en los recursos del FMI sigue parado a la espera de la aprobación de EEUU. Una de las líneas de trabajo más importantes que se abre para 2016 es la de los recursos del Fondo. Los préstamos bilaterales que concedieron varios países miembros al FMl en 2012, por un importe inicial de 456.000 millones de dólares, que luego se han quedado en 380.000 millones de dólares efectivos, empiezan a caducar en 2016. Será necesario negociar si se renuevan los préstamos o si se desea transformar estos recursos en aportaciones más permanentes como cuotas o los Nuevos Acuerdos de Préstamo (NAP o NAB por sus siglas en inglés).

Otra reforma del FMI que ha captado la atención de los mercados financieros y de los expertos es la revisión de la cesta de los derechos especiales de giro (DEG). Los DEG son un activo de reserva con el que cuentan los bancos centrales de los miembros del FMI, cuyo valor se determina como una media de las principales monedas de reserva de libre circulación (ahora mismo el dólar, el euro, el yen y la libra esterlina). Dado el enorme tamaño de la economía china, su condición de segundo productor industrial y exportador mundial (tras la zona euro), y las medidas de liberalización que han venido adoptando sus autoridades, se ha planteado la posibilidad de incorporar al yuan-renminbi (RMB) en la cesta del DEG. Pese a que esta moneda todavía mantiene restricciones a su libre convertibilidad, el personal del FMI ha anunciado su apoyo a la entrada del RMB en la cesta del DEG. Esta entrada puede constituir un símbolo $\triangle$ 
muy significativo de la elevación del estatus de China en la arquitectura financiera internacional, y un reconocimiento de su importancia clave.

Entre las políticas del FMI, se ha suscitado el debate sobre el papel del Fondo en la promoción de reformas estructurales dentro de su supervisión y dentro de la condicionalidad de sus programas financieros. Los consejos del Fondo en materia fiscal, monetaria y del sector financiero han contado con amplio respaldo y autoridad, dado que estas materias se consideran el «núcleo» de su mandato. No obstante, las recomendaciones sobre reforma estructural del Fondo han sido objeto de mayor debate, por no formar parte del núcleo de su mandato, por la vaguedad de algunas recomendaciones, o por existir cierta carencia de formación en la institución sobre las mismas. La institución ha decidido adoptar el criterio de que las políticas estructurales sobre las que adopte recomendaciones deben ser «macrocríticas». Es decir, de considerable importancia para el desempeño macroeconómico. En aquellos campos en los que el FMl aprecie que se cumple el criterio «macrocrítico», desarrollará capacidades en su personal y fomentará la colaboración con otras organizaciones internacionales. Esto puede constituir un refuerzo del papel del FMI en materia de reforma estructural, y sus recomendaciones en este campo pueden ser a partir de ahora más elaboradas.

El Comité Monetario y Financiero Internacional (CMFI), que reúne a los principales ministros y gobernadores de bancos centrales de los países miembros bajo la presidencia del gobernador del Banco de México, Agustín Carstens, ha apoyado esta orientación de las políticas del FMI, y también ha animado a la institución a estudiar la situación del sistema monetario internacional, que constituye el núcleo histórico de su mandato. EI CMFI ha pedido a la institución que analice si la arquitectura de la red mundial de seguridad financiera es la adecuada. Es decir, que analice si son suficientes los recursos con que cuentan el FMl y otros organismos regionales (como puede ser el Mecanismo Europeo de Estabilidad -MEDE-) para hacer frente a crisis internacionales de balanza de pagos.
EI CMFI ha respaldado el trabajo del FMI en apoyo de las cumbres internacionales de desarrollo, en particular de la Cumbre de Financiación al Desarrollo de Addis Abeba y la Cumbre del Desarrollo Sostenible en Nueva York, que se celebraron en julio y en septiembre. También ha pedido que la institución preste atención a las consecuencias macroeconómicas de las transiciones demográficas, además de las migraciones y de las corrientes masivas de refugiados, y ha apoyado que el Fondo contribuya con sus análisis en el plano macroeconómico a la Conferencia de las Partes (COP21) de París sobre cambio climático. Este tipo de contribuciones han suscitado debate dentro de la institución por estar alejadas del mandato original de la institución, pero son defendidas por la gerencia del Fondo como una participación en los debates de mayor actualidad, a los que el FMI puede aportar una perspectiva macroeconómica internacional.

\section{Conclusión}

Las Asambleas de Lima marcan un momento de fuertes cambios en la economía mundial. Las principales preocupaciones de los ministros de economía y finanzas han pasado de los países desarrollados, afectados por la inestabilidad financiera desde 2007, a los países emergentes. Los productores de materias primas, que hasta hace dos años contaban con fuertes superávits fiscales y exteriores, y enormes acumulaciones de reservas, también se encuentran bajo presión. La región iberoamericana ha estado en el centro de atención, para mostrar que, pese a la importancia que las materias primas tienen para la zona, no se debe caer en la generalización, y las circunstancias de cada país pueden diferir muy considerablemente. La organización de las Asambleas por parte de Perú ha mostrado la mejora institucional de la región y la capacidad de acoger un evento masivo, de logística muy compleja.

Estas Asambleas se han caracterizado por la espera de la inminente ratificación de las reformas $\triangle$ 
de cuotas y gobierno del Fondo Monetario Internacional por parte de Estados Unidos, y por la emergencia institucional de China, que podría ver el año que viene cómo su peso en las cuotas del FMI aumenta muy considerablemente, pasando a ser el tercer mayor país accionista y cómo su moneda pasa a formar parte del selecto club de los derechos especiales de giro. Los fuertes cambios en la economía mundial, y la emergencia del gigante asiático, van permeando de forma perceptible y significativa la arquitectura financiera internacional. 


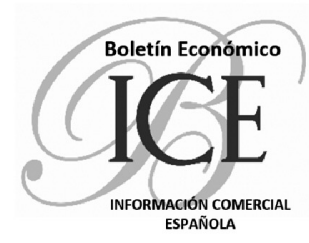

Información Comercial Española Revista de Economía

6 números anuales

Artículos originales sobre un amplio espectro de temas tratados desde una óptica económica, con especial referencia a sus aspectos internacionales

Boletín Económico de Información Comercial Española

12 números anuales

Artículos y documentos sobre economía española, comunitaria e internacional, con especial énfasis en temas sectoriales y de comercio exterior
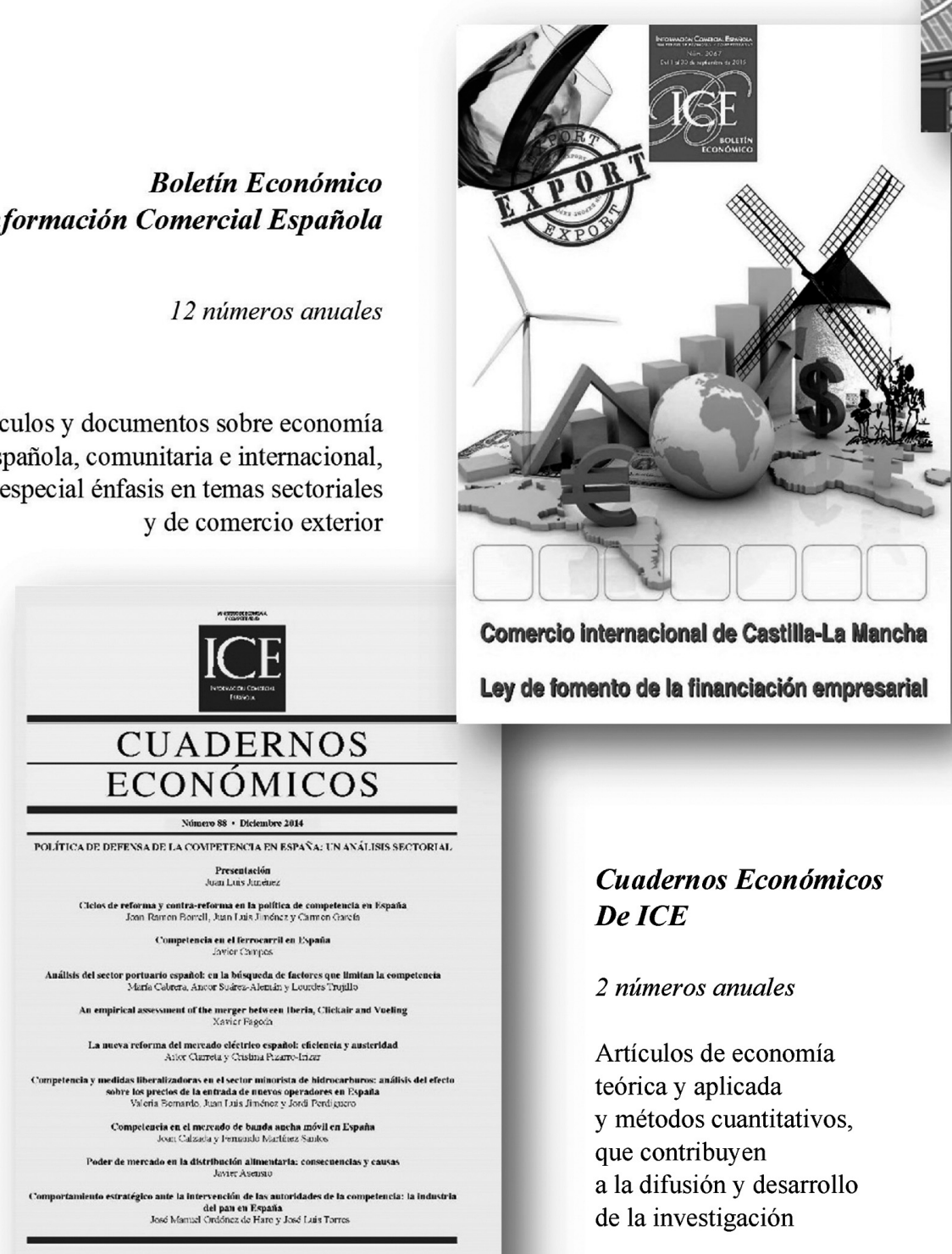

UNA POLITICA ECONÓMICA PARA LA RECUPERACIÓN

Comercio internacional de Castllla-La Mancha

Ley de fomento de la financiación empresarial

\section{Cuadernos Económicos \\ De ICE}

\section{2 números anuales}

Artículos de economía teórica y aplicada y métodos cuantitativos, que contribuyen a la difusión y desarrollo de la investigación 